International Journal of Engineering \& Technology, $7(3.29)(2018) 46-48$
SPC
International Journal of Engineering \& Technology
Website: $w w w . s c i e n c e p u b c o . c o m / i n d e x . p h p / I J E T$
Research paper

\title{
Experimental studies on reactive distillation of propionic acid using n-butanol as entrained
}

\author{
Raju.Kalakuntala $^{1 *}$, R. Navya ${ }^{1}$, T. Sisira ${ }^{1}$, V. V. Basava Rao $^{2}$, Srinath.surnani $^{1}$ \\ ${ }^{1}$ National institute of Technology Warangal, Telangana, India \\ ${ }^{2}$ University college of Technology, Osmania University, Hyderabad, Telangana, India \\ *Corresponding author E-mail: raju.kalakuntala@gmail.com
}

\begin{abstract}
Reactive distillation is a cost effective chemical engineering process intensification method which involves the reaction and separation simultaneously in a single unit. In the present work the system selected was Propionic acid and n-butanol which undergoes esterification reaction to form butyl propionate. Propionic acid is an important raw material from a biodegradable polymer. The experiments were done in both conventional batch distillation and reactive distillation. In conventional batch distillation no catalyst were used were as in reactive distillation amberlite catalyst used with various weight percentage. several experiments performed by varying the initial concentration(i.e. $0.1,0.2,0.4,0.6,0.8,0.99)$ of Propionic acid, mole ratios of Propionic acid \& n-butanol(that is 1:1,1:1.5, $1: 2$ And amberlite catalyst weight percent (i.e. 1,2 and 3).the conventional batch distillation and reactive distillation were compared. it is found that maximum conversion obtained in conventional distillation process is $81 \%$ and in reactive distillation is $95.1 \%$ at the optimum conditions are at initial concentration 0.6 ,mole ratio 1:2 And amberlite catalyst weight percentage 3 .And the recovery of water is more in reactive distillation as compared with the conventional batch distillation. So reactive distillation process is better than conventional distillation.
\end{abstract}

Keywords: Reactive Distillation; Propionic Acid; Process Intensification-Butanol

\section{Introduction}

Reactive distillation becomes a procedure where the chemical reactor is also the still Separation of product from response mixture does not require separate distillation step, which saves energy (for heating) and materials. This method is extant especially helpful for equilibrium limited equilibrium-limited responses like esterification including organic compound hydrolysis reactions. Conversion can be available increased far beyond what is predicted through the equilibrium directly to the constant removal of response goods from the reactive region. This help reduces capital and investment costs and may be important for Sustainable development due to a lower consumption of resources. The appropriateness of RD for a single response depends on numerous factors like volatilities on reactants including products up with the possible response including distillation temperature therefore the usage of RD for every response may not exist feasible. Exploring candidate reactions for Reactive distillation, though made-up in 1921, the commercial application on reactive distillation not happens earlier than the 1980s. In new decades, a mix of separation and reaction inside a only unit has come to be more and more popular. This combination has been accepted by the chemical process industries are considering the economics of carrying through reaction parallel with separation appropriate to certain classes of operating systems, and many recent procedures have invented based on this technology.

Reactive Distillation (RD) is theintegration of reaction of reaction $\&$ distillation within a single unit, which it takes pleasure in the number about specific advantages over the conventional serial appearanceof reaction, follows distillation or other segregation techniques. selectivity, conversion, heat control, efficient usage of response heat, the scope for hard segregations and the refraining of azoetrope are present in a few of the benefits that are offered by RD. The start of an in-situ separation process in response zone or the other way round leads to manifold interactions between vapor-liquid stability, mass transfer rates, scattering and chemical kinetics, which pretend to be a difficult provocation for design including synthesis of these systems [2]. The fitness of RD on behalf of an isolated response be determined by numerous factors like volatilities of chemicals and products along accompanied by the possible reaction and distillation temperature. [3] Therefore, usage of Reactive, distillation for every response may not exist feasible. Reconnoitering the candidate responses for $\mathrm{RD}$, it live an area that requires complete thinking to spread out the field of RD processes.

\section{Materials and methods}

Materials: The esterification reaction of Propionic acid and butanol is conducted in The presence of Amberlite catalyst in a batch reactive distillation apparatus with Glass Packed column (Borosil). The Propionic acid and butanol used in the experimental work are obtained from MERCK. The experimental set-up used is shown. The experimental setup includes of $2000 \mathrm{~mL}$ three napes round bottom vessel placed on a heating duty with a stirrer. The beginnings of three neck Thermos flasks are used for thermowell for putting a thermometer, another opening was linked to the column, packed accompanied by glass rings along with other appropriate to fixing silicon rubber with for collecting. A doubled surface condenser was placed on top of the column intended condensing the mists for. The condensed hazes are allowed settled within a glassware tube attached to the support. The water including butanol separates according to density difference Water there is removed from the lower layer and butanol sent back into. The whole packed column from a 
flask to is thermally insulated to avoid heat losses. The capacitor cooling aqua is distributing via norms concerning a pump. Doubled surface condensers are used appropriately to efficient condensing the in the operation. The whole arrangement containing a packed column is properly insulated to avoid heat losses. batch reactive distillation over entire reflux conditions. But the set up helps to get the water from condensation along with separates continuously.

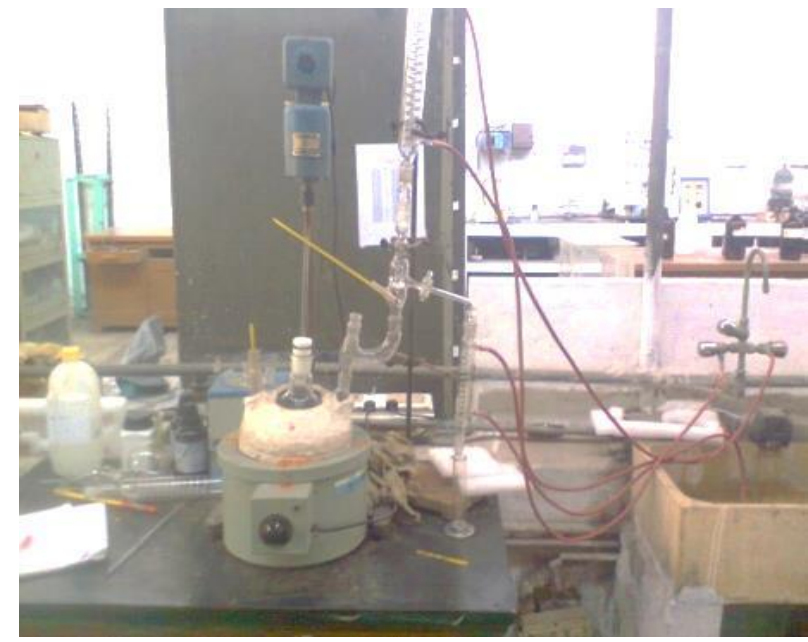

Fig. 1: Experimental Photo.

Methods: Propionic acid required quantity ( initial concentrations $0.1,0.2,0.4,0.6,0.8,0.99)$ of butanol for desired mole ratio(1:1,1:1.5and $1: 2)$ along with weight of catalyst percentage (1 $\mathrm{wt} \%, 2 \mathrm{wt} \%$ and $3 \mathrm{wt} \%$ )are charged to flask, after mixing the reactants are heated then generate vapors to pass through packed column for the separation of Aqueous phase by condensing from more volatile products. The residue samples were taken for different times to analyze the Free Propionic acid and Total Propionic acid mole fractions. The condensed solution from the condenser is extant allowed to move through an apparatus to get water at the lowest part of a proportional tubing accompanied by a drain tap and the highest liquid is as expressing the column. The process was continued to collect water up to a point where removal of water is very slow. This process which operates without catalyst will be known as the conventional batch distillation and in presence of catalyst will be known as the reactive (catalytic) distillation

Analysis:

Total Propionic acid (TPA): Weighed sample is taken into $100 \mathrm{~mL}$. Conical flask and $55 \mathrm{~mL}$. of water is added. From the mixture of sample $10 \mathrm{ml}$ of residue sample taken Now $30 \mathrm{~mL}$. of $0.5 \mathrm{~N}$ aqueous $\mathrm{NAOH}$ is added to flask. The solution is placed on a heater and brought to slow boil for $2 \mathrm{~min}$. The sample is allowed to cool and the excess $\mathrm{NaOH}$ is titrated with standard $0.5 \mathrm{~N} \mathrm{HCI}$ to the first disappearance of pink color with phenolphthalein indicator.

Free Propionic acid (FPA): Weighed amount of sample is taken into a conical flask and $25 \mathrm{ml}$ of water is added. The solution is titrated with $0.5 \mathrm{~N}$ standard solutions to the first appearance of pink colour with phenolphthalein indicator.

Poly Propionic acid (PPA): The difference between the total Propionic acid and the free Propionic acid is said to be a poly Propionic acid.

\section{Results and discussion}

Water recovery at various initial concentration: Effect of concentration and catalyst for recovery of water obtained for Conventional Batch distillation and reactive distillation Process of Initial Concentration 0.6 mole ratio $1: 2$ and different wt $3 \%$ of amberlite catalyst.for the different initial concentrations the recovery of water is increasing from 0.99 to 0.1 .where as in catalytic distillation recovery is more as comparing with the convential batch distillation.

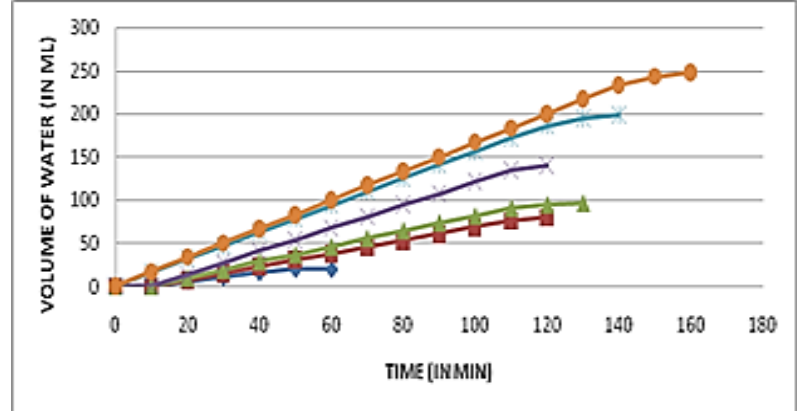

Fig. 2: Recovery of Water at Initial Concentrations.

Effect of molar ratio: The simple distillation of Propionic acid solution to separate water. Effect of mole ratios obtained for Conventional Batch distillation and reactive distillation Process of Initial Concentration 0.6 mole ratio $1: 2$ and different wt $3 \%$ of amberlite catalyst

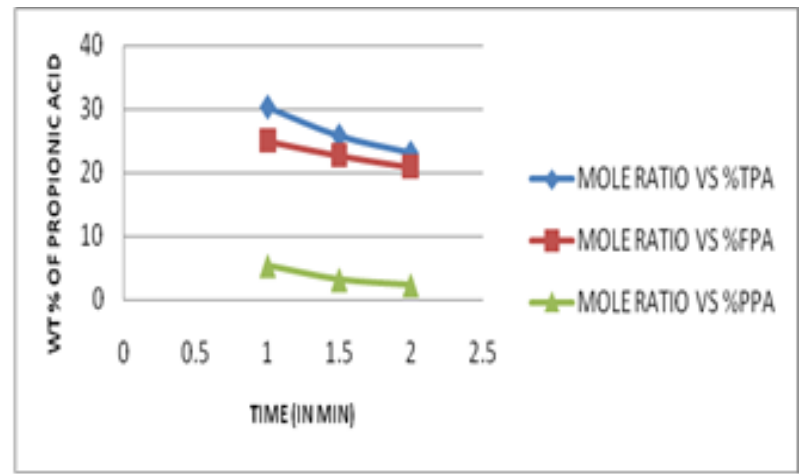

Fig. 3: Effect of Mole Ratio.

Amount of conversion obtained for Conventional Batch distillation and reactive distillation Process for Initial Concentration 0.4 mole ratio $1: 2$ and different $3 \mathrm{wt} \%$ of amberlite catalyst.the maximum amount of conversion is obtained at the various mole ratio,initial concentration and catalyst wt $\%$

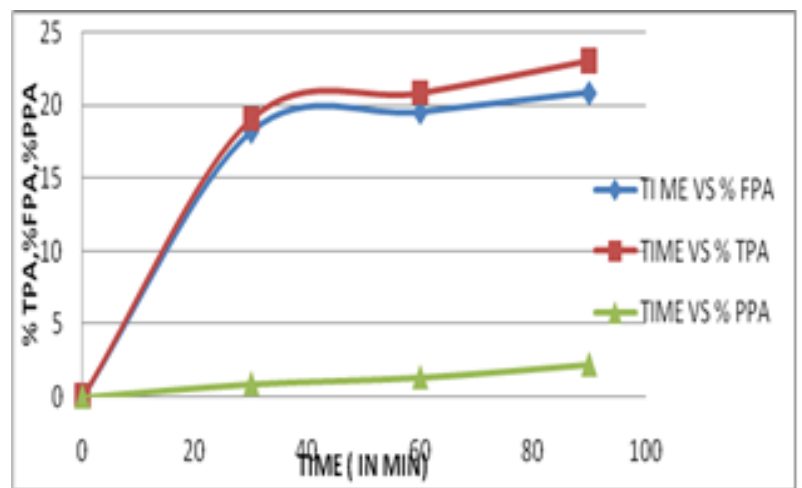

Fig. 4: Amount of Conversions percentage FPA, Percentage TPA \& Percentage PPA.

Catalyst weight effect: Shows advantage of using Amberlite IR-120 resin catalyst reactive distillation. The figure shows clearly Amberlite catalyst decreases amount of formation of Poly Propionic Acid to a lower value ratherthan for without catalyst. The catalyst is reducing $5-10 \%$ of poly Propionic acid formation than without catalyst and therefore catalyst is useful in the operation. The minimum Poly Propionic Acid is formed in the system for [2] weight percent to 3 weight percent but after 3 weight percent its formation remains constant. It may be due to the formation of equilibrium between Free Propionic Acid and Poly Propionic Acid. Therefore, the [3] weight percent catalyst is optimum in the operation. 


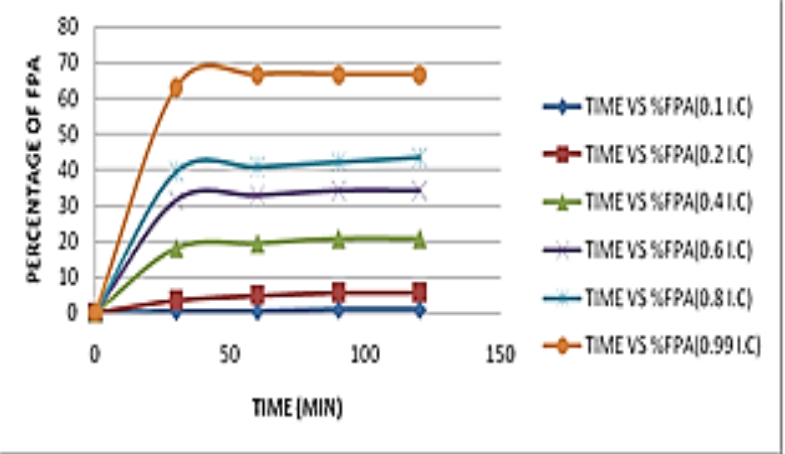

Fig. 5: Catalyst Loading Effect.

Effect of catalyst wt percent to the mole ratios: Shows the effect of catalyst weight percent. As catalyst, weight percent increases the Poly Propionic Acid reduced to low value and water removed increases to maximum. The minimum Poly Propionic Acid is formed in the system after [3] weight percent its formation remains constant. It may be due to the formation of equilibrium between Free Propionic Acid and Poly Propionic Acid. Therefore, the [3] weight percent catalyst is optimum in the operation.

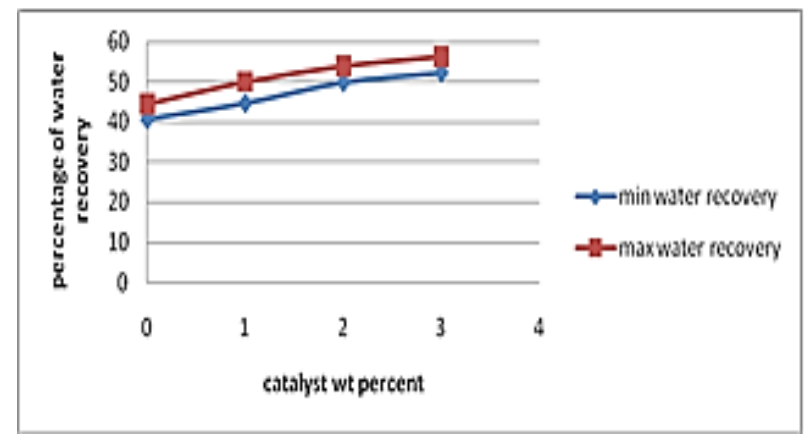

Fig. 6: Effect W.R.T Catalyst WT Percentage.

\section{Conclusion}

The importance of reactive distillation has been found that the Recovery of Propionic acid from aqueous solution is experimentally carried by using batch reactive distillation and conventional batch distillation.

1) It is observed from the initial experimental data obtained that as the water removal increases with time, the percentage of free Propionic acid and total Propionic acid

2) In addition, as the weight of catalyst increased, the yield of recovered Propionic acid is increased.

3) In action, it is observed that as feed concentration of the Propionic acid and reactant molar ratio decrease, recovery yield of the Propionic acid increased.

4) The yield of recovered Propionic acid is estimated as high as $95.1 \%$ in the operation when all the evaporated water is condensed and removed from the system.

5) For 0.6 initial concentration of the Propionic acid aqueous solution the optimum operating conditions are found to be [2] mole ratio and 3 weight percent of catalyst.

\section{References}

[1] V.V. Basava Rao, P. Shiva Kumar, Ch. Sailu and S. Ram Mohan Rao, 2014. Recovery of Lactic Acid by Reactive Distillation. Journal of Applied Sciences, 14: 1289-1293.

[2] Agreda, V.H., L.R. Partin and W.H. Heise, 1990. High-purity methyl acetate via reactive distillation. Chem. Eng. Prog. 86: 40-46.

[3] Us8048655 26AUG 2009 1NOV 2011 ZEACHEM,INC.recovery of organic acids.

[4] WO2012164573A reliance industries hydrolysis and esterification with acid catalysts.
[5] Reactive distillation for methyl acetate production Robert S. Huss, Fengrong Chen, Michael F. Malone, Michael F. Doherty Department of Chemical Engineering, University of Massachusetts, Amherst, MA 01003, USA. 